\title{
Bioprecipitation-a promising technique for heavy metal removal and recovery from contaminated wastewater streams
}

\begin{abstract}
With balanced industrial and infrastructural growth and stability in many developing countries, metal reserves are fast depleting and some of the metals are predicted to be exhausted in a few decade. Metal recovery from waste (liquid) streams, for example - acid mine drainage, is one classical option to achieve sustainable resource utilization. Bioprecipitation is a novel approach to recover metals with the help of biologically produced sulfide in suitable bioreactor configurations. Using this technique, stable metal precipitates are formed, which can be subsequently recovered for further industrial use.
\end{abstract}

Keywords: metals, bioprecipitation, sulfide precipitation, metal recovery, acid mine drainage, technological and societal challenges
Volume 2 Issue 6 - 2017

\author{
Suthee Janyasuthiwong,' Eldon R Rene \\ 'Department of Environmental Technology and Management, \\ Kasetsart University, Thailand \\ ${ }^{2}$ Department of Environmental Engineering and Water \\ Technology, UNESCO-IHE Institute for Water Education, \\ Netherlands
}

Correspondence: Suthee Janyasuthiwong, Department of Environmental Technology and Management, Faculty of Environment, Kasetsart University, Bangkok 10900, Thailand, Tel +6625793877, Email jsuthee@hotmail.com

Received: April 03, 2017 | Published: June 05, 2017

\section{Introduction}

Technological advancements, rapid industrialization in developing countries as well as countries in transition, urbanization and global population growth has started to cause an imbalance in the availability of global natural resources. The production rate of metals can no longer be compared to the daily, rapid utilization rate and it is noteworthy to accentuate the fact that many resources have already started to show its deprivation. Presently, the shortage of metals is being felt in many developed or industrialized nations due to over demand and this has resulted in the escalation of global metal market prices. Leading metal mining companies are trapping the unexplored metal reserves in developing countries and selling them at the international market due to the attractive price. As a consequence of this mass mining, exploration and acquisition activity, several metals will be soon exhausted from the earth's surface.

On the other hand, metal contaminated wastewater especially from anthropogenic source like acid mine drainage (AMD) is a persistent issue, specifically in developing countries and in places where there are abandoned mining sites. Other sources of metal containing waste stream includes industries such as metal finishing, metal plating, semiconductor manufacturing, steel making, electrical power plants, quarry related operations, etc, among others (Figure 1). Due to its tendency to bioaccumulate and biomagnify in the food chain, metal toxicity has caused adverse effects to both living beings and the environment.

Nowadays, due to the arising knowledge on metal contamination and metal scarcity issues, recovery of metals from the waste stream and reusing the metals has been the focus of several research groups and process industries. Such an effort will not only contribute to sustainability of metal reserves, but it will also avoid further resource depletion. Among the different techniques and technologies proposed in the literature for the removal and recovery of metals from contaminated waste streams, biological treatment, specifically bioprecipitation, is an environmental friendly approach. From a process and mechanism view point, this approach relies on the use of sulfate containing wastewater to produce sulfide through the anaerobic pathway and subsequently the metals are recovered in the form of metal sulfide precipitates.

\section{Bioprecipitation for metal recovery}

In general, precipitation is one of the easiest approaches for wastewater treatment wherein the focus or objective of the treatment is to recover valuable by-products from the waste stream. In conventional precipitation, this technique often requires the addition of chemicals to improve the settling ability of the precipitates and therefore, it eventually leads to high operational costs, the idea of using biological processes to facilitate metal precipitation was thought upon for environmental engineering applications. As the name suggests, bioprecipitation uses microorganisms, especially bacteria. During bioprecipitation the produced metabolites react with metals present in the wastewater and forms metal precipitates, i.e. it converts the metals from its aqueous phase into solid phase. According to Kumari et al., ${ }^{1}$ microorganisms can facilitate the metal immobilization step via carbonate precipitation. However, the most stable product is metal sulfide over others strategies that use carbonate, phosphate or hydroxide. ${ }^{2}$ In this domain of research, sulfate reducing bacteria (SRB) is commonly mentioned in many metal bioprecipitation publications due to its metabolic pathways that produces sulfide during the anaerobic treatment of sulfate containing wastewater.

\section{Opinion on technological challenges}

Although this technology has proven to be very efficient in several laboratory scale a investigations, there are still some challenges for its application in full or industrial scale systems..$^{3-5}$

Scientific challenges: From a practical perspective, scientific or 
technical challenges are mainly related to the performance of the bioprocess used, such as process stability, longevity of bioreactor operation, its efficiency in handling wastewater containing a broad range of metals and other pollutants (example: AMD, metal processing waste discharges, landfill leachate), downstream processing to improve the metal recovery efficiency and the activity of the microorganisms. ${ }^{6,7}$

Microbial growth factors: Metabolic engineering of microorganism are key to the success of any bioprocess. The efficiency of metal removal and recovery depends on microbial growth, its ability to handle toxic metals, resilience capacity of the microorganisms to withstand harsh operating conditions and the amount of precipitates (i.e. sulfide or carbonate) formed that can directly react with the pollutants (metals). In the case of AMD, its common characteristics are low $\mathrm{pH}$ and high concentrations of different metals and metal species.

In-situ or ex-situ treatment: The prevailing harsh environmental conditions in AMD may affect the survival of some microorganisms; on the other hand, such environments can also host adverse population of acidophilic, metal tolerant species. As indicated by Baker \& Banfield, ${ }^{8}$ such environments can serve as a model system to study metal-metal interactions, biogeochemical interactions and feedbacks and microbial community structure and its functions. Thus, considering the practicality of applying an appropriate bioreactor configuration to treat metal contaminated waste streams, the foremost question in one's mind should be: should metal containing wastewater be treated in-situ or ex-situ?. Celis et al. ${ }^{9}$ \& Janyasuthiwong et al. ${ }^{10}$ have tested a "proof-of-concept" of applying down flow or inverse fluidized bed (IFB) reactor configuration, for the treatment of low $\mathrm{pH}$, sulfate rich wastewater supplied with an external carbon source, in order to produce sulfide and facilitate metal precipitation within the same unit. Similarly, for the sake of convenience and to avoid process disturbances, a two-step process can also be used to recover metals in the form of metal precipitates in bioreactors operating in sequencing batch mode (Figure 1).
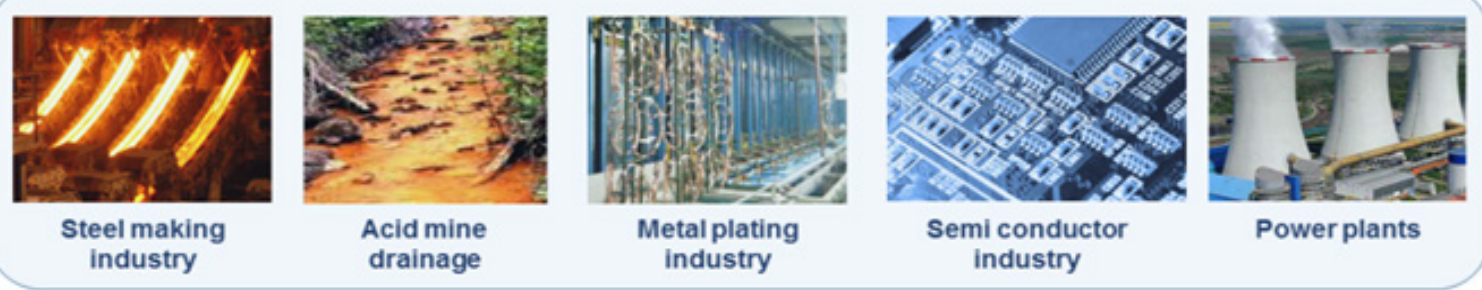

Sources of

metal

containing

wastewater
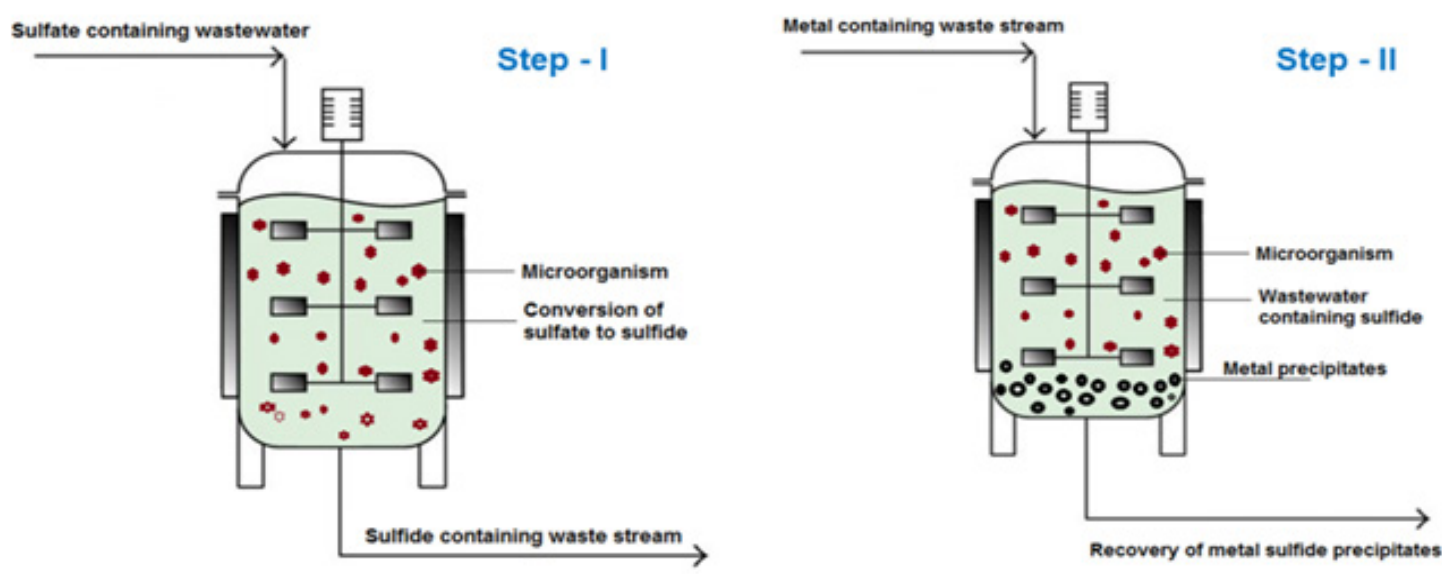

Sequencing

Figure I Source of metal containing wastewater and the application of bioprocesses for the removal and recovery of metals.

Enzymatic approach: This approach is an emerging trend in applying SRB technology for practical purposes, i.e. to solve the issues of low sulfide production or low bacterial growth rate when the microorganism is in direct contact with the untreated AMD. This approach can be divided as follows: (i) to genetically modify the bacteria and enhance its capacity to survive in harsh conditions and (ii) vigorous enrichment of the bacterial cultures and extract the enzyme for further use. Wang et al. ${ }^{11}$ has demonstrated the use of metabolically engineered SRB to produce sulfide under aerobic condition via cysteine, desulfhydrase. According to Joutey et al., ${ }^{12}$ bioaugmentation and biostimulation are methods that can be applied to accelerate the recovery useful byproducts from polluted sites. According to the authors, there are four principal approaches that are applied to genetically modified microorganisms, namely, (i) modification of enzyme specificity and affinity, (ii) pathway construction and regulation, (iii) bioprocess development, monitoring and control and (iv) sensor applications for chemical sensing, toxicity reduction and end point analysis.

Bioreactor designs: Considering the process economics for implementing any new reactor at the industrial scale, the ease reactor operation, efficient separation or recovery of the byproducts and less space requirements are considered to be beneficial for companies and investors. In the case of applying bioprecipitation, the major issues that should be addressed or taken into prior consideration are the direct contact of the feed wastewater to the microbial zone, crystallization and crystal growth zone and the separation of precipitates from the biomass. In recent years, SRB technology has been acknowledged by many researchers for its efficiency in metal recovery. Anew, there are other reactor configuration that can achieve enhanced sulfide production and ease of biomass or metal-precipitate separation. For 
instance, in an IFB reactor configuration, the feed wastewater enters the reactor from the top and recirculates continuously depending on the hydraulic retention time (HRT), while the SRB grows in attached mode on a low density carrier material which is suspended in the liquid phase. The metal precipitates settles at the bottom facilitating the ease of biomass and metal separation. ${ }^{13}$

\section{Conclusion}

Environmental biotechnology uses biocatalysts for the remediation of a wide variety of pollutants of environmental interest. Bioprecipitation can be applied in both developing and developed countries; however, the cost-benefit of reusing or selling the recovered metals may vary depending on the company's investment on infrastructure. Besides, the separation and purification steps dictate the costs of secondary metals in the global metal market. Future research in this field should be aimed at performing costbenefit analysis of the bioprocess, process integration for resource recovery, the development of phenomenological models to describe the bioprecipitation mechanism and investigation on the enzymatic pathways involved.

\section{Acknowledgements}

None

\section{Conflict of interest}

The author declares no conflict of interest.

\section{References}

1. Kumari D, Qian XY, Pan X, et al. Microbially-induced carbonate precipitation for immobilization of toxic metals. Adv Appl Microbiol. 2016;94:79-108.

2. Lewis AE. Review of metal sulphide precipitation. Hydrometallurgy. 2010;104:222-234.
3. Ballester A, Castro L, Costa MC, et al. Design of remediation pilot plants for the treatment of industrial metal-bearing effluents (BIOMETAL DEMO project): Lab tests. Hydrometallurgy. 2017;168:103-115.

4. Huang WH, Dong CD, Chen CW, et al. Application of sulfate reduction mechanisms for the simultaneous bioremediation of toluene and copper contaminated groundwater. Int Biodeter Biodeg. 2017.

5. Zhang G, Ouyang X, Li $\mathrm{H}$, et al. Bioremoval of antimony from contaminated waters by a mixed batch culture of sulfate-reducing bacteria. Int Biodeter Biodeg. 2016;115:148-155.

6. Gadd GM. Heavy Metal Pollutants: Environmental and Biotechnological Aspects. In: Schaechter M, editor. Encyclopedia of Microbiology. 3rd ed. USA: Academic Press, Elsevier; 2009. p. 321-224.

7. Wagner TP, Raymond T. Landfill mining: Case study of a successful metals recovery project. Waste Manag. 2015;45:448-457.

8. Baker BJ, Banfield JF. Microbial communities in acid mine drainage FEMS Microbiol Ecol. 2003;44(2):139-152.

9. Celis L, Villa-Gómez D, Alpuche-Solís A, et al. Characterization of sulfate-reducing bacteria dominated surface communities during startup of a down-flow fluidized bed reactor. J Ind Microbiol Biotechnol. 2009;36(1):111-121.

10. Janyasuthiwong S, Rene ER, Esposito G, et al. Effect of $\mathrm{pH}$ on $\mathrm{Cu}, \mathrm{Ni}$ and $\mathrm{Zn}$ removal by biogenic sulfide precipitation in an inverse fluidized bed bioreactor. Hydrometallurgy. 2015;158:94-100.

11. Wang CL, Maratukulam PD, Lum AM, et al. Metabolic engineering of an aerobic sulfate reduction pathway and its application to precipitation of cadmium on the cell surface. Appl Environ Microbiol. 2000;66(10):4497-4502.

12. Joutey NT, Bahafid W, Sayel H, et al. Biodegradation: Involved Microorganisms and Genetically Engineered Microorganisms. In: Chamy R, Rosenkranz F, editors. Biodegradation-Life of Science. Croatia: In Tech Publisher; 2013. p. 289-320.

13. Janyasuthiwong S, Rene ER, Esposito G, et al. Effect of $\mathrm{pH}$ on the performance of sulfate and thiosulfate-fed sulfate reducing inverse fluidized bed reactors. J Environ Eng. 2016;142(9):C4015012. 